\title{
Environmental Conservation in Buddhist Monasteries for Sustainable Tourism
}

\author{
Sutthanuch Wiriyapinit ${ }^{1}$ and Supot Chunhachoti-ananta ${ }^{2}$ \\ ${ }^{1,2}$ International College for Sustainability Studies, Srinakharinwirot University, Bangkok, Thailand
}

\begin{abstract}
Tourism in Thailand has grown dramatically since the 1970s. The country has been recognized as a 'dream destination' by foreigners due to its beautiful natural resources and historical locations. Though the industry is a major contributor to economic growth, Thailand has experienced the deterioration of historical attractions, particularly temples and their environment, due to a lack of preservation measures. Every day, thousands of tourists visit famous temples such as Wat PhraKaew and Wat Arun. As a consequence, these temples have faced many environmental issues such as overcrowding and waste management, and the inappropriate behavior of tourists. Therefore, the purposes of this research are 1) to investigate how environmental conservation in monasteries affects sustainable tourism and 2) to develop guidelines for promoting environmental conservation in temples to enable sustainable tourism

To achieve the aims of the study, qualitative research was conducted. Two research methods, documentary research and in-depth interviews, were employed. The interviews were conducted at six temples, three in Bangkok and three in other provinces. The research findings reveal that, despite the immense influence of monasteries and monks on Thai tourism, all three monasteries in Bangkok do not properly manage the environment surrounding them. Consequently, the pristine environment and artifacts have unintentionally been allowed to deteriorate. However, the three temples in the provinces show better environmental conservation practices which has resulted in sustainable development of tourism and a superior impression on tourists and greater tourist satisfaction.
\end{abstract}

Keywords: Sustainable Tourism, Temple Conservation

\section{Introduction and Rationale}

Tourism has been the most important sector for the economy of Thailand for the past decade or so. According to the World Travel and Tourism Council (WTTC) the direct contribution of tourism to Thailand's GDP was USD 34 billion (9.0\% of total GDP) in 2013. This is predicted to increase in the next decade to approximately USD 64 billion (10.4\% of total GDP) in 2024. Moreover, the total contribution in 2013 was approximately $20.2 \%$ of GDP which will grow by $6.4 \%$ annually to $22.7 \%$ of GDP by 2024 .

More importantly, tourism created 2,563,000 jobs (6.6\% of total employment) in 2013, and this figure is expected to increase to $9.0 \%$ of total employment in 2024. The total contribution of tourism to employment in Thailand, including jobs indirectly supported by the industry, is expected to reach 8,739,000 jobs in 2024 (20.5\% of total). This shows how much influence the tourism industry has on the wellbeing of the country. [1]

One of the major issues which concerns tourism stakeholders and public agencies such as the Tourism Authority of Thailand, is how to manage tourism sustainably [2]. A large number of tourism destinations have faced this problem which invariably stems from a lack of competent management. It can be said that the problem of unsustainable tourism is the result of improper management. If the problem persists many of Thailand's tourism destinations will not be sustained. The tourism industry in Thailand as well as around the world comprises various institutions and individuals. This research focuses solely on the Buddhist institutions in which monks ('Sangha' in Thai) and monasteries ('Wat' in Thai) play a significant role.

For hundreds of years, monks have been the social and spiritual leaders in the majority of communities in Thailand. Throughout the country, there are tens of thousands of temples in almost all communities, large and small. Even though at present, the role of monks as social leaders has declined, particularly in urbanized areas, the spiritual role is still maintained. Nevertheless, globalization has changed many aspects of Thai society, and religion and tourism are no exception. 
Some sections of Thai society have been unable to adapt to these rapid changes. These include the Sangha (Buddhist monastic corpus). Most tourists, both Thai and foreign, like to visit temples and monasteries. First time foreign visitors to the country are likely to visit the Grand Palace with its Temple of the Emerald Buddha, which is one of the highlights of Bangkok tourist attractions [3]. Many domestic tourists also prefer visiting famous temples such as major temples in their neighborhood and famous ones in Bangkok, namely Wat Prakaew, Wat Sutad, and Wat Arun, especially during Buddhist observances and their birthdays. While this provides welcomed income, there are also unanticipated impacts. The landscape of many temples has been improved to accommodate growing tourism activities which results in environmental impacts. Therefore, research on the role of monks in environmental conservation for sustainable tourism in the monasteries is a crucial part of the collective effort to make Thai tourism more sustainable. It is also interesting in that it can provide an example and a basis for participatory development of sustainable tourism in other institutions in society.

\section{Research Objectives}

1) To investigate how environmental conservation in monasteries affects sustainable tourism

2) To develop guidelines for promoting environmental conservation in temples to enable sustainable tourism

\section{Buddhism and the Environment}

Many Buddhists recognize that Buddhism and the forests have had an inseparable relationship for more than 2,500 years. Lord Buddha was born under a Cannon ball tree. The Great Master became enlightened under a Bodhi tree, and then gave his first Sermon in Isipatana Mrigadayavan, a deer park. Later, The Enlightened One attained complete Nirvana under a cannon ball tree. The first Buddhist temple, Veruvana, was built in a bamboo forest. Later on, many important and famous temples and monasteries were built in the forests, for example Chetavana, Cheewagambhavana, and Mahavana. As they were located in the forest, their names often end with 'vana' or 'vanaram' which means forest. It can be seen that forests have played an important role in the origin of Buddhism, dharma, and sangha (monks' assemblage). Forest was the locations where the foundations of Buddhism including the Sangiti, practicing dharma, self-discipline training, were laid. The development of Buddhism has occurred within the natural environment [4].

\section{Monks and Environmental Conservation}

Venerable Phra Brahmagunabhorn stated that since temples are central to the communities and society, they act as a role model for development in the communities [5]. Thus, the abbots and monks should possess the knowledge and skills required to lead communities effectively [6]. So, there is a need to train these Buddhist personnel so they are well-informed thinkers who recognize social changes and adapt accordingly. However, sometimes, using knowledge from different sources can have both positive and negative outcomes. The Sangha had previously been barred from access to other sources of information except the Buddhist scriptures, and when this restriction was removed, information from other sources of knowledge, especially the Internet, has surged into the monasteries like gushing currents without levees [7]. Without careful contemplation, the new knowledge may be used to change the monasteries and communities in a way that is not consistent with sustainable development. For instance, some monasteries thought that development is cutting down trees to make way for a parking lot or large buildings. On the other hand, those with wisdom can utilize this new information to support existing knowledge. This will enable them to become effective leaders of their temples and communities.

By the same token, Phra PaisanVisalo of Sukhato Forest Monastery in Chaiyabhum province is a good example of a monk's role in environmental conservation. He encouraged the communities in Kaeng Khro subdistrict to reduce the areas farmed for cash crops (cassava and sugar cane), and promoted diversified agriculture which can help prevent the destruction of soil which occurs with mono cropping. The communities can farm and harvest all year round without having to invade the forest areas [8]. Phra Visalo also initiated the project 'Dharma walk for Songkhla Lake', leading 20 monks and 120 lay people on a hundred-kilometer walk to raise the environmental awareness of the communities around Songkhla Lake. Villagers now have an understanding 
of the necessity of preserving their fragile environment in order for them to be able to utilize the water and other resources from the lake for their own wellbeing [9].

\section{Definition and Characteristics of Sustainable Tourism}

Since it is one of the world's largest industries, tourism has the potential to affect destinations and people tremendously [10]. It can assist in alleviating poverty, conservation efforts, and the preservation of cultural heritage. On the other hand, it can also increase income inequality, natural habitat destruction, and the commodification of art and culture. Therefore, the application of sustainable development principles in the tourism industry is essential. Major institutions around the world, including various United Nations (UN) agencies, the United Nations World Tourism Organization (UNWTO), the Organization for Economic Cooperation and Development (OECD), and the European Union (EU) have responded to this need. Consequently, the definition of sustainable tourism was proposed.

The United Nations Environment Program (UNEP) and World Tourism Organization (UNWTO) define sustainable tourism as "Tourism that takes full account of its current and future economic, social and environmental impacts, addressing the needs of visitors, the industry, the environment and host communities" [11]. This definition covers a broad range of issues concerning how tourism can influence the environment, economy, and society both positively and negatively. According to this definition, tourism should follow the principles of sustainability below [11].

I. Creating optimum usage of the environment and natural resources which are key elements in tourism development.

II. Revering the socio-cultural genuineness of host communities, their built and living cultural heritage, and traditional values.

III. Guaranteeing lasting economic operations which providing fairly distributed benefits to all stakeholders.

Furthermore, these principles of sustainability are relevant to 'all forms of tourism development' [12]. In addition, the development of sustainable tourism necessitates all stakeholders being actively involved in a consensual manner. Tourists are an important component in the process, and they should be aware of the principles in order to contribute towards sustainability. More importantly, the host communities and the caretakers of tourist attractions, including monasteries, must have a real understanding of the principles so as to carry out the tasks required to achieve sustainable tourism development while maintaining a high level of tourist satisfaction.

\section{The Importance of Monks in Promoting Sustainable Tourism}

In the Buddha's Era, temples may have been natural dwellings or pre-existing structures. Later, the religion grew and there were more and more monks, necessitating the construction of permanent religious buildings for spiritual practices and rituals. If the sponsors were of high position and power, e.g. kings, the buildings would be larger and more sophisticated and decorated with precious materials by the finest artisans of the time. Therefore, Buddhist monasteries are "not only spiritual spaces but also tourism resources reflecting the civilization and livelihood of the locale which accumulate historical, educational, artistic, and architectural information and connect the originof the community's culture and settlement' [13]. Nevertheless, there has not been much work that addresses this potential to create sustainable tourism practices [14]. One of a small number of research articles was by Sujitra Yamngarmleau [15] which collected the opinions of tourists and relevant organizations on religious tourism. This survey was divided intoseven issues. Three issues pertaining closely to this research are 1) the promotion of tourism in Buddhist monasteries should provide correct information to the tourists about the history of temples and their significance to the local communities, 2) the maintenance of the monasteries' should be standardized and strictly enforced in order to make them clean and tidy and appropriate for both locals and tourists, 3) the promotion of tourism in religious places should bring about spiritual benefits and the perpetuation of the religion, and should also encourage inter-faith understanding. Therefore, this research will focus on these issues in greater detail. 


\section{Methodology}

This research is descriptive research using qualitative methods consisting of two stages as follows. The first stage involved the study and review of literature related to monasteries which are major tourist attractions, including their histories, paintings, and sculptures as well as their surroundings. Afterwards, qualitative data was collected in the field through in-depth interviews with monks, tourists, and community leaders in order to investigate the environment inside the monasteries which affects sustainable tourism, and the guidelines for promoting the roles of monks in environmental conservation in the monasteries to enable sustainable tourism

In-depth interviews were employed for data collection as wisdom regarding the environment and conservation in monasteries is sophisticated. Therefore it is best to extract the data from the stakeholders who have direct experience dealing with the aforementioned issues in monasteries.

\section{Data collection and analysis}

Six monasteries, which varied in size, location and level of popularity, were selected. Three of them are located in Bangkok and are larger and more popular than the other three monasteries which are located in the provinces [4]. Interviewees included monks ranking from Venerable Teacher to Abbot. Their responsibilities include managing the monastery and tourists visiting the monasteries. We also interviewed the leaders of neighbouring communities who play a role in the management of temples. These various groups of stakeholders provide for diverse perspectives, namely the monk's perspective and the layperson's perspective, which strengthens the reliability of data analysis and research results. In total, there were 17 interviewees as follows.

1. RatchanuddaramWoraviharn Monastery, Bangkok (two monks and one tourist)

2. Bawornnivesviharn Monastery, Bangkok (two monks and one tourist)

3. Chanasongkram Monastery, Bangkok (two monks and one tourist)

4. Prakeaw Monastery, Chiang Rai province (one monk and one tourist)

5. Phong Sanook Monastery, Lampang province (two monks and one community leader)

6. Yanwesagavana Monastery, Nakorn Pathom province (one monk and two tourists)

The data collected was transcribed and then analyzed in conjunction with the data from the literature review for each monastery. Descriptive Content Analysis was used to examine the results.

The data from in-depth interviews was analyzed and summarised to answer the research objectives. During the analysis, it was found that historical details could have close linkages with the data. Therefore, historical knowledge was integrated with the data on environmental conservation and sustainable tourism guidelines in monasteries.

\section{Data triangulation}

Data from the different sources - the literature and interviews with various groups of stakeholders, were analyzed and compared with each other in order to enhance the reliability and depth of the research findings [16, 17].

\section{Research findings and Discussion}

The findings of this research can provide answers to the two research objectives (RO1 and RO2) as discussed below.

\section{RO 1: To investigate how environmental conservation in monasteries affects sustainable tourism}

From the research results, it can be concluded that monasteries in Bangkok have been influenced by commercial factors resulting in the deterioration of the relationship between monasteries, Buddhism, and the environment. Even though importance is given to the maintenance of the environment inside these monasteries, it is only aimed at promoting temples as a symbol of Thai tourism. For example, there is a tour package to visit nine famous temples in Bangkok which only involves gazing and taking photographs of nice Thai traditional buildings. This type of tourism does not allow for tourists to appreciate and understand the core of Buddhism, Buddha's dharma or the serenity of the monasteries, which could lead to an understanding how humans live with 
nature. If tourists understand this, they will be impressed and may want to re-visit Thai monasteries which manifest a virtuous environment. This would better encourage sustainable tourism.

At the same time, the results show that the monasteries in the provinces have conservation practices that can support sustainable tourism development. An important finding from this research is that one factor for a successful environmental conservation practice in monasteries is the collaborative management between monks and laymen. This particular idea has not been covered in prior academic and research work, which has mainly emphasised the role of monks in safeguarding the environment in monasteries.

Furthermore, from the interviews, it was realised that the environment surrounding monasteries in Bangkok and that of the monasteries in the provinces are different. This seems a crucial factor in the different conservation outcomes. By outside environments we mean people living in proximity to the monasteries. People living in Bangkok mostly think about commercial activities related to monasteries and Buddhism. This creates an obstacle for environmental conservation towards sustainable tourism development since the monasteries and monks only develop the area for tourists and those who come to visit these places for the magnificent architecture. This development practice does not aim to educate tourists so they can appreciate dharma, nor does it encourage them to contemplate deeply about life. Both of these outcomes would support sustainable tourism in Thailand.

In contrast, people in the provinces still see monasteries as a part of their daily life. They perceive the monasteries as a common property which means that they are carefully taken care of and are preserved in their original state. This gives visitors a genuine experience of a Thai monastery which involves observing the peaceful and serene atmosphere. The experience of this tranquil environment will encourage visitors to learn and understand more about Buddhism and dharma which in turn will motivate the development of a more sustainable type of tourism in these monasteries. As mentioned earlier, sustainable tourism development underlines cultural authenticity more than the built environment [11]. Dharma can present Thai cultural identity in terms of the thinking and attitude of people who live peacefully. The research found that this is the case in Pong Sanook and Prakaew monasteries in Lampang and Chiang Rai provinces respectively. So visiting these monasteries can instill tourists with the spiritual values of Thai Buddhism which can subsequently promote sustainable tourism.

In terms of the guidelines for promoting the roles of monks in environmental conservation for sustainable tourism in Thai temples, the research found that there has to be good management for the promotion of monks' role in taking care of the monasteries' internal environment. The results affirm the concepts and ideas about Buddhism, nature, and conservation as mentioned earlier. More importantly, the research also finds that monks are not the only stakeholders who should advocate conservation.

The findings, however, point to the fact that environmental conservation in monasteries should be under a collaborative administration between monks and lay people as was found in the monasteries upcountry. The findings also suggest the importance of applying management concepts and principles in creating strong teamwork. For example monks who are in charge should uphold good governance and noble leadership principle, which in turn can encourage other monks and lay people living around the monasteries to take part in the collaborative conservation effort for sustainable tourism development.

In addition, the findings highlight the importance of giving rewards. On appropriate occasions, giving rewards encourages environmental conservation for sustainable tourism development. For instance Pong Sanook monastery received a certificate from UNESCO, and a monk was promoted to a higher rank due to his distinguished work on environmental conservation. This inspired other monasteries and monks to follow suit. This finding has never been mentioned in other previous works.

\section{RO 2: To develop guidelines for promoting environmental conservation in temples towards sustainable tourism}

From the results and findings, guidelines including two main recommendations are set forth to help environmental conservation in Thai monasteries move towards sustainable tourism as follows.

\section{Creating a knowledge network}

In order to promote a collaborative effort and improve teamwork for environmental conservation, a recommendation should be made to the Maha Dhera Samakom (Sangha Supreme Council) asking for more 
collaboration with agencies responsible for tourism development. For example, Thai tourism agencies could offer a management system for tourism in monasteries equal to the international standard. When a knowledge network among the monks and other relevant stakeholders is created, tourism in Buddhist monasteries can be enhanced and made more sustainable as it can improve the authentic cultural value of this type of tourism.

In order to build a knowledgeable society, it is important to build the knowledge base first which will then support the practical endeavour. Therefore, knowledge management, in which the wisdom is transferred from the people who know to the people who practice, is a success factor in the management of these cultural 'capitals' $[18,19]$. These capitals are essential to Thailand not only in terms of tourism, but more importantly in terms of creating and maintaining an identity.

\section{Raising awareness and understanding of environmental and cultural conservation}

It is recommended that the Sangha Supreme Council have a policy to educate monks of various ranks on environmental and cultural conservation. This should be one of the criteria for the promotion of monks which presently emphasize the building of new structures in monasteries. If this is the case, monks will be encouraged to conserve and maintain a peaceful environment instead of having new and possibly inappropriate buildings. Moreover, tourism agencies should take part in this effort to raise the understanding of sustainable tourism development and should not be afraid of censuring monks on these issues. Also, if the Fine Arts Department also lists some of the significant monasteries as national heritages, this could potentially halt unsustainable development as it may be deemed illegal to modify a national heritage site [4]. More importantly, all aforementioned stakeholders should come up with a plan to sustain the environmental and cultural conservation efforts which will reflect the truly collaborative work between all stakeholders.

In conclusion, the management of an environment suitable for practicing dharma is the main role of Buddhist monks. This type of environment also encourages an authentic experience for visitors as well as sustainable tourism development. Concurrently, appropriate conservation practices can be carried out with collaboration between monks and lay people. This overall system will eventually create sustainable tourism in Thai monasteries and may be set a good example for other tourism sectors and attractions to follow.

\section{References}

[1] World Travel and tourism Council. (2014). Travel \& Tourism Economic Impact 2014: Thailand. [Online]. Available http://www.wttc.org/-/media/files/reports/economic\%20impact\%20research/country\%20reports/thailand2014.pdf

[2] Tourism Authority of Thailand. (2011). Annual Report 2011. [Online]. Available http://www.tourismthailand.org/About-TAT/annual-report.

[3] Tourism Authority of Thailand. (2015). Bangkok. [Online]. Available http://inter.tourismthailand.org/fileadmin/upload_img/Multimedia/Ebrochure/2/BangkokEn.pdf.

[4] A.Wiriyapinij, "Environmental Conservation in Buddhist Monasteries for Sustainable Tourism," Personal Interview. 3 May 2009.

[5] Phra Brahmagunabhorn, "Buddhist morality. Bangkok,”Bangkok: Chulalongkorn University Publishing, 1999.

[6] P. A. Panyatharo, "The abbot and leadership of the community is central to the development of the community: A case study Wat Dhammayut in Phatthalung province," M.S. thesis, Rajabhat Thonburi, Bangkok, Thailand, 2003.

[7] R. Thurman, "Buddhist views on the environmental crisis", in F. B. Miracle, (ed.) Conference Proceedings on Human Values and the Environment, pp. 23-31,1992.

[8] Phra Paisan Visalo, Buddhism in Thailand Trends and exit from the crisis, Bangkok: Sodsri Foundation - Sarit Wong, 2003.

[9] N. Chetchotiros. (26 March 1996).Abbot teaches peace and conservation in a materialist era, Bangkok Post Newspaper, pp. 20.

[10] World Economic Forum. (2012). The ASEAN Travel \& Tourism Competitiveness Report 2012: Fostering prosperity and regional integration through travel and tourism. [Online]. Available: http://www3.weforum.org/docs/WEF_TTCR_ASEAN_Report_2012.pdf

[11] United Nations Environment Program (UNEP) and World Tourism Organization (WTO), “Tourism and Sustainability," in Making Tourism More Sustainable - A Guide for Policy Makers, UNEP and WTO, 2005, ch 1, pp. $7-23$. 
[12] V. Castellani, and S. Sala, "Sustainable performance index for tourism policy development," Tourism Management, 31(6), pp. 871-880, 2010.

http://dx.doi.org/10.1016/j.tourman.2009.10.001

[13] C. U. I. Wong, A. McIntosh, andC. Ryan, (January 2013). Buddhism and tourism: Perceptions of the monastic community at Pu-Tuo-Shan, China. Annals of Tourism Research. [Online]. 40(1), pp. 213-234. Available http://www.sciencedirect.com/science/article/pii/S0160738312001387

[14] I.Baedcharoen, (April 2004) "Impacts of religious tourism in Thailand," Masters Dissertation, University of Otago. New Zealand, [Online]. Available http://hdl.handle.net/10523/1302

[15] S. Yamngarmluea, "The opinions of the tourists and relevant organizations on religious tourism," Tourism Authority of Thailand Tourism Journal, no. 4, pp. 3, June 2008.

[16] R. K. Yin,Case study research: Design and methods, 3rd ed. Thousand Oaks, CA: Sage, 2003.

[17] C. Marshall and G. B. Rossman, Designing Qualitative Research, 3rd ed. Thousand Oaks, CA: Sage Publishing, 1999.

[18] W. R. King,In "Knowledge transfer": The encyclopedia of knowledge management, ed. D.G. Schwartz, Hershey, PA: Idea Group Publishing, 2006, pp. 538-543.

[19] S. Oliver, and K.R. Kandadi, " How to develop knowledge culture in organizations? A multiple case study of large distributed organizations,"Journal of Knowledge Management 10(4), pp. 6-24, 2006.

http://dx.doi.org/10.1108/13673270610679336 